Madrygal. Revista de Estudios Gallegos

ISSN: 1138-9664

\title{
Narrativa
}

\section{O lado positivo}

Marcelino Fernández Mallo
O día 10 de decembro de 2015, Ricardo Tabarés escribiu no seu muro do Facebook:

Quero comunicar aos meus amigos do Face que padezo un cancro incurable que provocará a miña morte nun prazo indefinido dalgúns meses. Non é a mellor noticia que me deron na miña vida inda que tamén ten o seu lado positivo. Vós non sabedes cando marcharedes para o outro barrio nin que mal será o que vos leve. Vivides na incerteza, eu xa non.

Recréome nestes momentos no gozo das despedidas que protagonizarei desde unha posición de completa autoridade moral e espiritual, unha autoridade que estou a adquirir por medio deste propio post. A partir de agora, nada pode facerme dano, son un home inmune.

Haivos máis vantaxes, mirade. Escribín dúas novelas que titulei "Incerta probabilidade" e "Baixo terra". Permanecen inéditas porque non houbo editorial que as quixera publicar. Agora as posibilidades aumentan notablemente. $\mathrm{O}$ morbo é unha das técnicas de marketing máis efectivas.

Se lamento isto de morrer á metade do camiño é porque me quedan experiencias en forma de consellos que compartir coa miña filla. Estou decidido a explotar a oportunidade que me brinda a vida tamén neste particular. Elaborarei unha listaxe longa de recomendacións para ela e publicareinas a disposición de tódolos fillos de pais a piques de falecer, xa o saiban eles ou aínda non. Este novo libro titulareino "Consellos para orfos".

Agora, se premedes o botonciño de Gústame, espero que vos refirades aos aspectos favorables que veño de sinalar e non ao propio feito de desaparecer das vosas vidas unha vez se extinga a miña.
Ricardo Tabarés posuía 442 amigos no Facebook dos cales 188 premeron o botonciño "Gústame". O post recibiu así mesmo 115 comentarios, todos eles sen excepción felicitando a Ricardo pola deportividade coa que aceptaba o seu sino. Algúns tamén lle desexaban un tempo de permanencia entre os vivos nas mellores condicións posibles. E un par deles mesmo lle recomendaban dedicarse ós praceres tolos do sexo, a droga e o rock \& roll, por esta orde. Ricardo respondeulles: "xa volo dicía, se é que todo son vantaxes!”

Consello 1. Non prestes atención ao que proclamen voces seguramente interesadas na túa domesticación. Podes estar segura de que, en ocasións, o fin si xustifica algúns medios.

Varios dos seus amigos do Facebook, quen realmente o coñecían, compadecían a Ricardo Tabarés polo triste fado que lle tocara en sorte. Obrigado a casar aos 22 anos tras deixar preñada unha moza esfarrapada e indolente de 19, o tempo do matrimonio fóralle unha especie de calvario no cal soamente lle faltou ter sido cravado a unha cruz para exposición e escarnio público. A Claudia culpouno de non levar o preceptivo preservativo cando aquel primeiro encontro, de ter perdido o control da súa pelve arrebatada e de non decidirse a descabalgar antes de perpetrar a obtusa insensatez. Adiou o que puido a visita ao xinecólogo esperando que lle baixase a menstruación en calquera momento. Nada máis acordar cada unha daquelas angustiosas xornadas, bulía a comprobar o grao de humidade do recanto máis insondable do seu corpo. Así cinco meses tralos que o aborto se tornou unha ameaza antes ca 
unha solución. A nena naceu por cesárea e foi bautizada cristiamente co nome de Nélida, iluminada polos deuses segundo o amante pai.

Non viría a conto describir o que foron aqueles vinte anos de convivencia familiar. Vaia a modo de síntese esta frase lapidaria: "falta por nacer o home capaz de aguantar esposa igual de desvergonzada nos asuntos da sociedade e outrosí tan desalmada no que consonte á relación conxugal". O Ricardo aturou por dúas razóns poderosas: a primeira, por cousa de atender como merecía ó produto do seu desenfreo. Vistas as diarias ausencias da nai, a Nélida tería complicado satisfacer as necesidades básicas de non compartir o lar co pai. E segunda, pola cuestión dos cartos que con frecuencia lle afanaba á súa dona incapaz ela de levar conta do saldo en euros do seu bolso. Cando a Claudia lle fuxiu con aquel representante de complementos dietéticos, Ricardo Tabarés percibiu un sentimento híbrido froito do resultado dunha análise espontánea. "Véxolle vantaxes e inconvenientes", ese foi o seu primeiro pensamento.

A Claudia sacara un diploma de fisioterapia expedido pola Cross-fit School despois de seis meses de audicións e prácticas. Axiña atopara un posto no Cross-fit Club asociado á Academia. Traballaba sen horarios nin contratos mais nunca obtiña menos de 2.000 euros ao mes, iso segundo os cálculos do Ricardo. El traballara como asesor comercial en varias axencias inmobiliarias ata o estoupido da coñecida burbulla. Fíxose autónomo como última saída pero había meses que os ingresos nin sequera lle daban para pagar a cota mensual. Pateaba as rúas buscando carteis de venda ou aluguer, chamaba ofrecendo os seus servizos, baixaba a comisión ata valores contrarios á dignidade profesional e nin así conseguía pechar operacións. Furgar no bolso da muller non lle gustaba nadiña pero tampouco non atopaba outra solución mellor á súa fraxilidade financeira.

Consello 16. Le refráns con frecuencia e procura aplicar as súas ensinanzas. Pensa que recompilan décadas, mesmo séculos, de sabedoría popular. Dous exemplos: "ao feito, peito"; "de perdidos, ao río".

Sempre lle tirara a cousa literaria, lía acotío e de xéneros distintos. Mesmo se matriculara un par de anos na Facultade de Filoloxía onde apenas aprobara catro ou cinco materias. Dado que dispuña de tempo libre pola involuntaria falta de ocupación, empezou a escribir historias. Principiou por unha novela negra que titulou Incerta probabilidade. Trataba sobre un axente inmobiliario que apenas conseguía vender un piso cada catro ou cinco meses. Ante a falta de liquidez, escolle unha vítima propicia, asasínaa de modo algo trapalleiro e asume a personalidade do morto a fin de poñer no mercado as súas propiedades...

Mentres enviaba o manuscrito ás editoras que atopaba na Internet, comezou unha nova novela, esta titulada Baixo terra e tamén do xénero que agora chamaban noir. Resulta que o protagonista, un afable xardineiro, dedicábase a roubar nas casas ricas que lle solicitaban o arranxo de cadanseu xardín. Adopta distintos nomes e fasquías co propósito de non facilitar a súa identificación. Agocha o roubado nun abeiro subterráneo que construíra na súa finca, a cal aínda figuraba ao nome do pai falecido. $\mathrm{O}$ escondedoiro resulta imposible de detectar sen dispoñer duns avanzados coñecementos de xardinería. O plan consistía en acumular os obxectos e ilos clasificando por categorías para poñelos á venda un par de anos antes do retiro coa sa intención de gozar dunha fantástica xubilación...

Remitiulles de todo, en formato postal e online, variando portadas, tipografías, modos de encadernación e sobres de envío. O motivo do silencio editorial, pensaba Ricardo, podería residir en calquera factor subxectivo. Alá foron cartas de presentación, biografías literaturizadas, sinopses, primeiros capítulos, fragmentos escollidos, informes de lectura, recomendacións falsificadas, comparacións pormenorizadas e tamén os manuscritos completos ás compañías que non advertían expresamente de arquivar os recibidos no depósito da reciclaxe. Tres anos porfiou ata que se convenceu do incontestable: a ninguén lle interesaba nada o que el escribira.

Consello 34. Se a realidade fose un cosmético, sería crema redutora. Así pois, pensa e proxecta en grande. Para rebaixar intencións e obxectivos, xa terás iso: a realidade.

Así que o Ricardo vía vantaxes e inconvenientes na intempestiva fuxida da Claudia. Por unha banda, pensaba el, deixo de sufrir a agonía da espera continua, despídome de golpes (si, claro, a Claudia batía no home cando lle petaba) e humillacións, podo escribir sen acenos de mofa ao meu arredor, saberei manter 
a debida orde na casa e na súa organización, disporei dunha despensa equilibrada, saudarei os veciños sen receo das súas miradas intencionadas, durmirei tranquilo dun tirón e, finalmente, acadarei o que sempre ambicionei: un ambiente propicio para a Nélida. Súa nai nin sequera lle concedeu o beneficio dunha despedida máis ou menos afectiva. Entre as dúas mulleres apenas se cruzaban esporádicos xestos de recoñecemento, o máis frecuente viña sendo a mutua indiferenza, o cal funcionaba a modo de armisticio convido trala súa última e envilecida discusión. A Claudia non deixaba de considerar que a vida lle sería bastante máis doada sen a presenza da filla encol da cortiza terrestre. A Nélida mantiña activo o desprezo que sentía pola nai non so debido ao déficit de cariño que lle amosaba senón especialmente por mor dunha existencia que desaprobaba e na cal subliñaba o trato despectivo que dispensaba ao seu pai.

No apartado dos inconvenientes, Ricardo identificou axiña a cuestión financeira. Complicábaselles o pago de facturas e recibos e tamén a adquisición dos alimentos precisos mesmo optando a partir do momento polas outrora deostadas marcas brancas dos hipermercados. A Nélida non lle fixo graza ningunha pero aceptou ao tempo que pensaba na posibilidade de buscar un traballo que compaxinar cos estudos. E chegou a noite e con ela outro inconveniente. O Ricardo púxose a lembrar os bos instantes compartidos, admitía que algún houbera. Cando a Claudia batía contra el, facíao como por aburrimento, case sen forza, os brazos máis ben querendo aloumiñar que mancar. Golpeáballe sobre todo o peito, carnoso e mol, e un pouco nos bíceps. Podíaselle escapar un crochet á faciana, daquela a Claudia detíñase, parecía temerosa. A verdade que aquilo era unha malleira sen mallar, unha loita sen loitar. Nin sequera sabía a Claudia por que batía no home de cando en vez. El apenas se defendía, nada máis a agarraba e o intento semellaba sobre todo un inicio de aperta. Un bico solto confundíase cos xestos de disimulo e había ocasións, así de Pascuas a Ramos, que o bico transcendía. Ás veces Claudia terminaba musitando "se aínda foses algo máis afouto" ou frases do estilo.

Consello 52. Evita as escusas e sobre todo as explicacións salvo cando sexa imprescindible. Unha explicación amosa a túa debilidade e tórnase información que se pode volver contra ti no momento máis inconveniente.
Catro días despois de ter publicado o post co anuncio premonitorio da súa morte, Ricardo Tabarés recibiu a chamada de Xan Caballa. Caballa viña sendo un profesor e, nos últimos anos, tamén editor. Gustáballe iso das coincidencias vocálicas, por dicilo dalgún xeito; as palabras que non portaban máis ca un tipo de vogal. Coma o seu propio nome. Coma o nome comercial da súa compañía editora, Prólogo. Coma o blog literario que administraba, Que debes ler. Coma os nomes dos seus fillos, Amanda e Clemente.

Ricardo Tabarés solicitara polo Facebook a amizade de Xan Caballa un mes antes. Engadira igualmente a Débora Álvarez, Lidia Egido, Óscar Freixeiro e Moisés Velo, editores os catro. Ricardo comprobou que Débora e Lidia lle trasladaran condolencias virtuais anticipadas por medio do botonciño "Gústame" pero fora Caballa quen dera o paso de poñerse en contacto con el.

Citáronse no bar da Facultade de Xornalismo onde Xan Caballa daba clase de Historia da Comunicación Social e de Literatura e Medios de Comunicación. A cafetería ofrecíase baleira de clientes a aquelas horas. Chegou primeiro o editor quen asistiu decepcionado á entrada de Tabarés, acompañado este por unha rapaza alta e bonita, de pelo castaño e mirada un chisco suspicaz, pareceulle. A decepción de Caballa explicábase pola falta de decrepitude no escritor a quen supuña pouco menos que acabado. Esperaba que a ameaza do final lle tivese debuxado algún risco inequívoco na faciana. Mais aquel home non semellaba próximo ao derradeiro alento nin moito menos.

-Encantado, Ricardo. Alégrame ver o teu magnífico aspecto.

-A fachada nada máis, xa sabes que os medicamentos de hoxe en día conseguen auténticas milagres estéticas.

- Sempre está mellor a estas horas da mañá. Tiña que velo pola noite — apuntou Nélida dilixente.

-Atúame, por favor. Non son tan vello risas por triplicado.

-Así que es o editor de Prólogo. Coñezo ben a túa editorial. Publicas a Suso Conde e a Telmo Rivas, dúas garantías de éxito.

-Neste mundo só Pérez Reverte garante o éxito, máis a estrela do momento, por suposto. Agora María Dueñas, xa veremos quen será o ano que vén. 
—Ricardo Tabarés, claro! —unha chanza algo forzada do autor agoniante.

—Pode ser, pode ser, quen sabe?

Falaron unha hora longa. Ricardo, que traía as copias de Incerta probabilidade e de Baixo terra, entregoullas a Xan e resumiulle os argumentos. O editor faloulle da empresa socia de Prólogo, Abracadabra, que actuaba no mercado en castelán. Ofreceulle un anticipo de 2.500 euros. Non adoitaba facer tal cousa pero neste caso pareceulle axeitado. Ricardo agradeceulle o detalle e escusouse, tiña que ir ao baño, explicou.

- Non o vexo tan mal. Canto estiman que poida... durar? - preguntou Xan Caballa con certos atrancos.

-Non se sabe, cada día temos unha estimación. Poden ser dous meses ou seis ou incluso máis.

- $\mathrm{Si}$, claro, estas cousas... A min gustaríame planificar a publicación dunha maneira... lóxica. Tal vez podíamos lanzar Incerta probabilidade nunhas seis semanas, teu pai aínda podería participar no lanzamento, non cres?

-Non estou segura.

- Creo que será o mellor, traballar con ese horizonte temporal. Bueno - Ricardo reincorporábase con cara de circunstancias - estabamos deseñando o calendario. A intención será publicar unha obra canto antes. Hai que maquetar, deseñar portada, corrixir as galeradas e mandar o ferro ao prelo de impresión. O normal, unhas seis semanas, catro se apuramos prazos.

- Se cadra conviría apurar — matizou Ricardo.

- Vai ser o mellor, si — confirmou Caballa.

- Outra cousa, para rematar. Velaquí tes o número de conta da miña filla. Facede os ingresos nesa conta. Ela é a miña única herdeira. máis.

-Por suposto, claro, de acordo. Faltaría

Consello 74. Do que che conten, non creas nada; do que vexas, a metade. Dito doutra maneira: non confíes nin sequera no teu pai.

O lanzamento coordinado de Incerta probabilidade e de Probabilidad incierta resultou un éxito ben por riba das expectativas. Prólogo e Abracadabra deron o dó de peito no labor de difusión e promoción, facendo xusto fincapé nas circunstancias persoais do autor. As entrevistas sucedíanse nos medios escritos. Por razóns que todos comprenderon, os cuestionarios eran enviados por e-mail e respondidos a través desa mesma canle. A editorial preparara unha colección de fotografías en distintas poses e contextos que, tralo correspondente filtro no photoshop, serviron para acompañar os textos das entrevistas. Caballa pensou que pronto necesitarían unha nova sesión fotográfica. Respecto aos medios audiovisuais, solicitábase realizar as entrevistas no propio domicilio do escritor. Ademais e novamente, Prólogo encargouse de gravar un par de horas de preguntas e respostas que de igual maneira foron dosificándose entre as canles de televisión, internet e radio.

Unha vez chegaron aos 100.000 exemplares vendidos, Xan Caballa tomou a decisión de adiantar a edición de Baixo terra e de Bajo tierra. Así llo comunicou a Nélida Tabarés, que se convertera no seu contacto directo, unha especie de representante do escritor. Nélida contestoulle tres ou catro días despois. Aceptaban o adianto sobre o calendario previsto inda que deberían realizar con urxencia as entrevistas sobre a nova novela. Estas haberían desenvolverse forzosamente vía email ou teléfono. Aproveitaba para informalo de que pai e filla se mudaban de residencia en cuestión de semanas. Supuña que comprendería as razóns. O escritor manifestaba o seu desexo de non recibir a ninguén a partir dese mesmo instante. Pregáballe ademais que trasladase á prensa a súa petición expresa para que non tentasen atopar o seu paradoiro. Esperaban a comprensión de todos e o respecto máximo á súa intimidade. Por último, informábao de que durante estes meses, o seu pai conseguira rematar unha nova novela, de título Intricadas aparencias, e que incluso estimaba poder corrixir un libro de relatos que escribira anos antes e que precisaba certo perfeccionamento. Cando o considerase oportuno, a propia Nélida se poría en contacto coa editorial para facerlle entrega dos respectivos manuscritos. Antes, no entanto, mandaríalle Consellos para orfos que o pai practicamente daba por rematado.

Consello 100. A mestría na vida acádase cando un é quen de tornar un risco de menoscabo das condicións existenciais nunha oportunidade para melloralas.

A pantalliña do teléfono marcaba un número longo que ela non identificou. A profusión do díxito 6 fixo que pensara no diaño como autor da chamada. Tampouco errou tanto. 
-Mamá, es ti?

- Son eu, túa nai, si. Canto tempo! Como está a miña filla?

- Se te refires a min, estaba ata agora mesmo na gloria bendita.

—En serio? Estás ben?

-Completamente, mellor que ben.

-A que se debe tanto confort?

-Explícocho: áchome sobre unha hamaca a dous, ponlle tres, metros dunha piscina recreativa, cunha piña colada á miña disposición e no momento cimeiro dunha novela de intriga que me está a prestar. O lugar é zona de costa, vexo o mar con tal de me erguer da hamaca, e o tempo vai perfecto para o meu gusto. Calcúlolle uns 26 graos e nin unha nube ameazando no horizonte.

A nai tardou un bo anaco en responder. O seu ton alterouse de xeito evidente. Mirou ao seu redor. Ela tamén estaba en zona de costa mais a súa posición difería notablemente da descrita pola filla. Ela ofrecía masaxes aos turistas, a maioría españois, de vacacións en Praia Bávaro onde ela residía, a 20 minutos en autobús, cun veterano loitador de capoeira que prestaba os seus servizos de entretemento no todo incluído dun hotel 3 estrelas superior. Falou de novo como despois de ter afiado as cordas vocais.

-Que fas aí?

-Vivo aquí.

-Que fixestes coa nosa casa?

-A nosa casa? A que abandonaches hai catro anos?

-... / ...

-O que sexa. Xa non vivimos alí.

-Onde vives logo?

-Pois aquí.

-Está ben. E con quen vives?

-Co meu pai, con quen vai ser? 